\title{
Sahha (jakuudi) identiteet ja institutsionaliseeritud šamanism ${ }^{1}$
}

\begin{abstract}
Aimar Ventsel
Teesid: Käsitlen institutsionaliseeritud šamanismi Ida-Siberis Sahha Vabariigis. Sahha Vabariigi suveräänsuse väljakuulutamisega 1991. aastal kaasnes rahvusliku eneseteadvuse tõus, mis seisnes paljuski sahha traditsioonide ja ajaloo rõhutamises poliitilistes protsessides. Sahha šamanism muutus lihtsalt religioonist etnilise identiteediga seotud sümboliks. Seoses sellega omandas šamanismi alustala - Rahvameditsiini Assotsiatsioon - väga ambivalentse positsiooni sahha ühiskonnas. Oma artiklis analüüsin assotsiatsiooni tegevuse erinevaid valdkondi (poliitika, kultuur, meditsiin) ja väidan, et samamoodi nagu assotsiatsioonile on vaja riikliku toetust, saab riik kasu Rahvameditsiini Assotsiatsiooni toetamisest.
\end{abstract}

Märksõnad: etniline identiteet, Jakuutia religioon, šamanism

Selles artiklis käsitlen unikaalset nähtust postsovetlikus ruumis - institutsionaliseeritud ja de facto riigistruktuuridesse lülitatud šamanismi Sahha Vabariigis (Jakuutias). Ma vaatlen, kuidas šamanism kui institutsioon on kaasatud rahvuse loomise projekti ${ }^{2}$ ja milline on etnilise identiteedi tähtsus nii šamanismi tugevnemisel kui ka tema poolriiklikul staatusel Sahha Vabariigis.

1991. aastal kuulutas Jakuutia ennast Vene Föderatsiooni suveräänseks subjektiks ja muutis nime Jakuudi ANSVst Sahha Vabariigiks. See ei olnud ainult nimemuutus, vaid ka vabariigi sisemine reformimine just poliitilises mõttes. Jakuutias on titulaarrahvas jakuudid (omanimetus sahha) olnud kogu aeg, k.a tsaari- ja nõukogude aeg, poliitikas mõjukas, sest jakuudi eliit on läbi aegade püüdnud koloniaalvõimuga kollaboreerudes säilitada juhtivat positsiooni (Forsyth 1992: 62, 380-381; Mowat 1970: 91, 95, 100, 114, 125, 130). ${ }^{3}$ Seda on jakuudid saavutanud hoolimata sellest, et põlisrahvas moodustab Jakuutia elanikkonnas alla 50\%. Jakuutia on tänapäeval üks olulisimaid Venemaa tooraineregioone, andes umbes 99\% Venemaa teemantidest, aga ka olulise osa kullast, söest, naftast ja värvilistest metallidest (vt Duncan 1994; Tichotsky 2000). Seoses sellega jaguneb Jakuutia ka tänapäeval kaheks: lääne- ja lõuna- 
poolsed regioonid on tööstuslikud ning seal domineerib venelastest ja ukrainlastest elanikkond, Ida- ja Põhja-Jakuutia on peamiselt agraarne (karjakasvatus, põhjapõdrakasvatus, jaht ja kalapüük), ning sealsetes väikestes asulates elavad peamiselt jakuudid (sahhad) või vähemusrahvused dolgaanid, jukagiirid, evengid, eveenid ja tšuktšid.

Üleminek Sahha Vabariigile tähendas sahha rahvusriiklike ${ }^{4}$ ambitsioonide esiletõusu (Khazanov 1995: 175-191). See väljendus riigi sahha identiteedi rõhutamises ja kõige jakuudipärase toetamises. Enamik riigifirmasid nimetati ümber ja uue nime osaks sai alati sõna 'sahha' (ingl 'Sakha'). Nii asutati Sahhatelekom, Sahha-Avia, Sahhapoligraf jne. Ka kultuurielus toimus märgatav "jakutiseerumine". Asutati uus kultuuriülikool ja esimest korda ajaloos õpetati seal jakuudi keeles. Ka juba eksisteeriva Jakutski Riikliku Ülikooli juurde asutati uusi jakuudikeelseid kateedreid. Teatrites hakati lavastama jakuudi mütoloogia ainelisi oopereid (näiteks rahvuseepose Olonhoo põhjal). Sahha sümbolid võeti kasutusele ka riigijuhtimise kõrgeimal tasandil. Nii hakkasid presidendid ja muud kõrged riigiametnikud, hoolimata sellest, kas tegemist oli jakuutide või venelastega, kandma avalikel pidulikel üritustel stiliseeritud jakuudi rahvarõivaid. Tavaliseks muutus külaliste tervitamine kumõssiga, hobusepiimast valmistatud kergelt alkohoolse joogiga, jällegi hoolimata sellest, kas vastuvõtjad olid venelased või jakuudid.

Kõrgendatud huvi jakuudi sümbolite vastu ja nende intensiivistuv eksponeerimine äratas ka rahva seas huvi oma juurte vastu. Peab mainima, et see huvi oli valikuline. Rahva seas leidsid ja leiavad siiani sooja vastuvõttu just need sümbolid, mis märgivad jakuutide erilisust, salapära ja kõrghetki ajaloost. Jakuudi ajaloolase ja kodu-uurija Gavriil Ksenofontovi poolt 1920. aastail kirjutatud ja nõukogude ajal keelatud raamat Ураангхай - сахалар. Очерки по древней истории якутов (Uraanghai-sahhalar. Jutustusi jakuutide muistsest ajaloost) avaldati 1992. aastal ja see muutus hoobilt rahvuslikult meelestatud jakuutide üheks populaarseimaks lektüüriks. Raamatus kirjeldab autor jakuute kui muistseid kangelaslikke sõdalasi, kes enne venelaste tulekut suutsid Siberis rajada oma kõrgkultuuriga riigi, mille väljapaistvad juhid (toioonid) ja šamaanid olid tuntud ka väljaspool Siberit. Pärast iseseisvuse ja Sahha Vabariigi väljakuulutamist haaras sahha teadlasi ja kirjanikke suisa jakuutide ajalugu ja päritolu heroiseerivate teoste avaldamise laine. Iseloomulik on siin raamat jakuudi rahva fenomenaalsusest ja unikaalsusest, mille on kirjutatud tuntud ajaloolane Mihhail Tõrõlgin (Tõrõlgin 2000). Oma teoses tõestab autor, et johtuvalt majandusest (kõige põhjapoolseim karjakasvatajate kultuur), päritolust (endised mongolite vägede eliitsõdalased) ja kultuurist (eriline šamanismi vorm, üks pikemaid eeposi maailmas jne) on jakuudid väljapaistev, ehkki globaliseerumisest ohustatud rahvas, kes peaks oma pärandi säilitamise 
nimel rohkem tööd tegema. Üks "rahvuspärandi" edasiandmise vorm oleks autori meelest riiklikult finantseeritud koolitus ja tervishoiuprogrammid.

Rahvuskultuuri arendamise kõrval intensiivistus ka sahha kultuuri praktiseerimine. Kuulsaim üritus on nähtavasti iga-talvine muusikafestival Tabõk, kus esinevad etnilist muusikat pop- ja rokkmuusikaga segavad jakuudi kollektiivid koos samalaadset muusikat viljelevate koosseisudega Siberi teistest osadest ning vahel isegi väljastpoolt Venemaad. Teatrites hakati lavastama jakuudi rahvuseepose Olonhoo ainelisi ooperid ja näitemänge (eriti suurenes Olonhoo tähtsus 2006. aastal, kui eepos kuulutati UNESCO maailmakultuurivaramu osaks), samuti jakuudi ajaloost kõnelevaid etendusi. Jakuudi rahvamuusikat populariseeriti suisa riiklikul tasandil ja riigi toetusel asutati mitmeid uusi rahvamuusikakollektiive. Samuti hakati igas rajoonis korraldama suurejoonelisi nn rahvusspordialade võistlusi, ja seal, kus need eksisteerisid juba nõukogude ajal, muudeti võistlused veel pompöössemaks.

Selles artiklis käsitlen ühte aspekti sahha rahvusidentiteedi rajamises, nimelt religiooni rolli riigi ja etnilise identiteedi kujunemisel.

\section{Jakuudi traditsioon ja selle erinevad tahud}

Üks rahvuskultuuri osa, mis iseseisvumise järel põranda alt välja tuli ja kiiresti üldise populaarsuse võitis, oli jakuudi rahvameditsiin. Rahvameditsiini praktiseerisid nõukogude ajal ravitsejad, keda leidus igas sahha külas. See oli enam-vähem illegaalne tegevus, mida kohalikud jakuutidest riigiametnikud tolereerisid, kuigi eriti ei toetanud. Külades tegutsesid ravitsejad laia profiiliga terviseparandajatena ja nende ampluaa võis ulatuda kupupanemisest kuni abistamiseni suitsetamise mahajätmisel. Inimesed käisid tavaliselt ravitsejate juures väikese tasu eest ja (nagu Eestiski) rahvameditsiinil puudus nõukogude ajal äriline külg.

Rahvameditsiini, esoteerika ja neošamanismi buum algas Jakuutias, nagu mujalgi Nõukogude Liidus, perestroika algul. Nagu informandid mulle jutustasid, olid just 1990. algusaastad see periood, mil mitmesugused ravitsejad tegutsesid eriti aktiivselt. Jakutskisse rändasid ja seal asusid tegevusse mitte ainult omad, jakuudi šamaanid, vaid ka "külalisesinejad" Mongooliast, Burjaatiast ja Tõvast. Pikemat aega olid šamanistlikud korterisessioonid ja massiravimised rahva seas eriti populaarsed.

Ravitsejad leidsid ja leiavad jakuutide seas sooja vastuvõttu. Väga suur osa inimesi suhtub nendesse positiivselt ja usub nende ravimisvõimetesse. Et enamik jakuute pärineb küladest, kus ravitsejad on kogu aeg olnud kogukonna liikmed, on suur osa inimesi selle fenomeniga ka kokku puutunud ja neil ei 
ole eelarvamusi rahvameditsiini kui tegevusala suhtes, küll aga mõnikord konkreetse ravija suhtes. Nii leidub alati inimesi, kes on ühe või teise ravija võimete suhtes enam kui skeptilised. Nii palju kui ma olen inimestega ravijatest rääkinud, ei ole ma kohanud ühtegi ravitsejat, kelle suhtes poleks kriitiliselt meelestatud inimesi. Paljudel juhtudel väljendub kriitilisus väljendis, et tegemist polevat ehtsa ravijaga vaid isehakanuga. 'Isehakanu' tähendab üldiselt, et kõnealune ravija tuleb suguvõsast, kus pole ennem olnud šamaane või ravijaid. Paljude inimeste seas valitseb tänini uskumus, et "šamaanivõimed on geneetilised", kui tsiteerida ühte mu informanti. Arvamus, et šamaanivõimeid antakse edasi põlvest põlve, on terves Siberis laialt levinud ning paljude inimeste silmis legitimeerib just ravijate olemasolu esivanemate seas ka tänapäevaste ravijate tegevuse. Ehk nagu ütles üks mu informantidest: "Šamaani geenid on tugevad, nad ei sure välja. Sellepärast ei suutnud ka nõukogude võim šamanismi välja juurida.”

Jakuudi keeles on erinevad sõnad šamaani ja ravija kohta. Oiün tähendab šamaani ja emtšit (tulenevalt sõnast emp - arstirohi) on ravija. Need kaks sõna ei ole sünonüümid. Oiün on isik, kes peale inimeste ravimise on kontaktis ka transtsendentsete jõududega ja suudab rituaalide abil nendega suhelda (Vinokurova 1994). Rituaalid viib jakuudi šamaan läbi vastavas rõivastuses, milleks on enamasti maani ulatuv rüü, hobusesaba jõhvidest piits ja kooniline peakate. Stiliseeritult on sellised riided kasutusel tänapäevalgi, eeskuju nende valmistamiseks on saadud vanadelt tsaariaegsetelt ja varastelt nõukogude aja etnograafilistelt fotodelt.

Etnograafid väidavad, et jakuudi šamaanidel oli oma hierarhia, mille tipus olid valged šamaanid (maan oiün). Analoogilist hierarhiat püüavad hoida ka tänapäeva jakuudi šamaanid, kes kuuluvad Rahvameditsiini Assotsiatsiooni. Eriti on hierarhiseeritus märgatav suurematel üritustel, kus ühed teenindavad teisi. Jakuutias elatud aja jooksul panin tähele, et jakuudid, eriti maaelanikkond, suhtuvad šamaani institutsiooni äärmise austusega. Eriti on see märgatav just vanade, juba surnud šamaanide puhul. Ma olin mitu korda tunnistajaks, kui inimesed, nii noored kui vanad, keeldusid möödumast vanadest šamaanihaudadest, mitmes piirkonnas kohtasin lugusid sellest, millised õnnetused on juhtunud inimestega, kes on julgenud hauapanuseid suveniiridena kaasa võtta, ning isegi kõige lärmakam joomaseltskond vakatab, möödudes metsatukast, kus teatakse olevat maetud muistne kuulus šamaan.

Ravijad on tavaliselt kohaliku tähtsusega rahvameditsiiniga tegelevad kogukonnaliikmed. Nende ravimismeetodite ja haiguste diapasoon on lai ning varieerub isikuti. Mõni on spetsialiseerunud teatud tõbede ja hädade kergendamisele, mõni aga leiab rohtu peaaegu kõigile haigustele. Üks huvitavaimaid juhtumeid minu välitööde praktikas oli Loode-Jakuutias Anabari (dolgaani- 
evengi) rahvusulussi keskuses Saskõlahhis (sahhad kirjutavad Saaskõlah) kohatud kohalik arst, kes pärast tööd ravis inimesi rahvameditsiini abil. Ta aitas kuppu pannes kõrge vererõhu vastu, andis nõu muudes ihuhädades, kuid öeldi olevat ka võimeline motiveerima inimesi jätma maha nii suitsetamist kui ka joomist. Just seda viimast abi tuldi tema juurest tihti otsima. Too arst oli austatud kogukonnaliige ning tema sõna kuulasid ka kõige hullemad alkohoolikud ja kaklejad, isegi purjuspäi. Siiski polnud tal sellist reputatsiooni nagu šamaanidel. Peamine vahe oli selles, et teda ei seostatud teispoolse maailmaga suhtlemisega. Erinevalt šamaanist ei suhtu jakuudid ravijatesse traditsioonilise ebauskliku hirmuga, samuti pole neil olnud pärimusekandja rolli. Ravijad on oma kogukonnas (mõnikord ka kaugemal) lihtsalt tuntud ja austatud ning nende reputatsioon tugineb isiklikele ravimis- ja inimestega läbisaamise oskustele.

\section{Rahvameditsiini Assotsiatsioon}

Enne kui minna Rahvameditsiini Assotsiatsiooni juurde, tahan selgitada, miks ma mõistan seda organisatsiooni neošamanistlikuna. Neošamanism on enamvähem esoteeriline ideoloogia, mida seostatakse ennekõike Michael Harneri ja Carlos Castaneda (Castaneda 1968, 1971; Harner 1980, 1999) nimedega. Neošamanismi iseloomustab ennekõike erinevate ja kohati vastuoluliste lähenemisviiside sidumine. Siberi erinevates piirkondades levinud neošamanismi iseloomustab kohaliku šamanistliku traditsiooni rikastamine teiste siberi rahvaste rituaalide ja ravivõtetega, millele lisatakse üldiselt hiina ja india meditsiini ning isegi austraalia aborigeenide folkloori elemente (didgeridoo ${ }^{5}$ kasutamine). Suhtumine uutesse šamaanidesse on vastuoluline. Mõned teadlased peavad neid põlisrahvaste traditsiooni jätkajaiks ja edasiarendajaiks (Bulgakova 2009), teised aga traditsioonist irdujateks (vrd Bravina 2005). Jakuudi neošamanismi ja traditsioonilise šamanismi vahe tuleneb minu silmis ennekõike nende erinevast sotsiaalsest tähendusest. Rahvameditsiini Assotsiatsioon ja selle liikmed ei ole enam seotud külakogukonna ja perekonnastruktuuridega, vaid tegemist on Jakutskis baseeruva organisatsiooniga, mille liikmed peavad ennast rahvusideoloogia kandjaks ja väljendajaks. Peale selle on neil olemas selgelt juhi poolt defineeritud ideoloogia ja kanoonid, mis on võõras jakuudi traditsioonilisele šamanismile (Bravina 2005; Vinokurova 1994).

Ravijate, rahvameditsiini ja šamaanide ühendused eksisteerivad mitmes Siberi regioonis (Burjaatia, Tõva, Hakassia), ent mitte kusagil pole neil sellist poolriiklikku staatust nagu on Rahvameditsiini Assotsiatsioonil Jakuutias. Rahvameditsiini Assotsiatsioon (Assotsiatsia Narodnoi Meditsinõ) loodi mitme 
rahvameditsiiniga tegeleva isikute liidu ühinemisel 1993. aastal. See juhtus ajal, mil jakuudi eneseteadvus oli haripunktis. Sahha Vabariik oli sel hetkel edukalt "jakutiseeritud": poliitiline võim oli jakuudi eliidi käes, enamik riiklikest ja ametkondlikest sümbolitest olid seotud jakuudi rahvuslike sümbolitega (Sahha vabariigi vapp näiteks põhineb rahvuseeposel Olonhoo, riigiettevõtete nimesse lisatud eesliidet sahha mainisin eespool, rahvusvärvid olid kõikvõimalikes kombinatsioonides laialt kasutusel jne).

Sel ajal tugevnes ka president Mihhail Nikolajevi separatistlik poliitika (Khazanov 1995: 181). Suveräänsuse egiidi all hakkas Jakuutia ajama teemandi- ja kullaäri Moskvast mööda, konstitutsiooni muudeti nii, et kohalik seadusandlus muutus ülimuslikuks föderatsiooni seaduste ees. Samal ajal koondas president jakuute ka kultuuriliste sümbolite ümber, millest olulisimaiks osutusid keel ja riiklikult konstrueeritud traditsioon. Lisaks sahha kultuuri (haridus, kunst) toetamisele kaasati identiteeti kandvate elementide sekka ka "muistne" jakuudi religioon. Tegelikkuses tähendas ja tähendab see teatud (sageli üsna meelevaldselt valitud) religioossete rituaalide või nende osade lülitamist ametlike pidustuste kavva. Tavaks on saanud näiteks puhastus- ja õnnistusloitsude stiliseeritud esitamine tähtsate riiklike pidustuste avatseremoonial, kusjuures tekst tuleb lindi pealt ja selle on sisse lugenud professionaalsed näitlejad. Selline teksti ja tegevuse eraldamine on vastuolus jakuudi traditsioonilise šamanismi praktikaga, traditsioone eirab ka õnnistusloitsude lausumine profaansete isikute poolt. ${ }^{6}$ Jakuudi "iidse" kultuuri rõhutamine religioossete rituaalide lülitamisega riiklike ürituste kavva tähendas Sahha Vabariigi puhul ennekõike oma mitte-vene identiteedi rõhutamist separatistlike meeleolude tugevdamiseks. ${ }^{7}$ Rahvusliku iseteadvuse süvenemine tugevdas ka Rahvameditsiini Assotsiatsiooni positsiooni.

Juba 1992. aastal võttis Sahha Vabariigi valitsus suuna jakuudi kultuuri esiletõstmisele just poliitilises mõttes. Sellesse valdkonda ei kuulunud mitte ainult õsõeahi ehk jakuudi kesksuve tähistamise rituaali (täpsemalt edaspidi) muutmine riiklikuks jakuudi identiteedi manifestatsiooniks. 1992. aastal korraldas Jakuutia kultuuriministeerium rahvusvahelise konverentsi "Šamanizm kak religija: genezis, rekonstruktsija, traditsii (Šamanism kui religioon: areng, rekonstruktsioon, traditsioonid)", mille avas kultuuriminister ise ja kus osalesid ka äsja põranda alt väljunud šamaanid. Levisid isegi kuuldused, et šamanism kuulutatakse varsti riigireligiooniks (vt Balzer 1993). Seda küll ei juhtunud, ent üritus ja sellele eelnenud kultuurikeskuste ja šamanismile pühendatud muuseumite arvu kasv ning konverentsile järgnenud šamanistlike organisatsioonide tegevuse intensiivistumine näitasid jakuudi poliitilise eliidi huvi kasutada poliitilise mobilisatsiooni instrumendina just jakuudi kultuuri. 
Jakuudi poliitilise eliidi huvi jakuudi kultuuri ning šamanismi vastu märkasid muidugi ka šamanistlike rühmituste juhid, kes ajapikku jõudsid arusaamisele ühise katusorganisatsiooni asutamise mõttekusest. Suurema, šamanistliku alatooniga ühendorganisatsiooni abil said iga masti ravijad paremini suhelda nii riigistruktuuridega kui ka korraldada oma tegevust rahva seas. Mingis mõttes näitab Rahvameditsiini Assotsiatsiooni loomine nn professionaalse konsensuse saavutamist erinevate ravijate, šamaanide ja meediumite vahel, kes olid nõus koonduma ühte organisatsiooni. Rahvameditsiini Assotsiatsiooni loomine ei läinud aga ilma konfliktideta. Ideoloogiliste vastuolude tõttu moodustas väike osa ravijaid ja meediumeid juba 1993. aastal oma liidu -Olohh Sire -, mis eksisteerib tänini ja mille tähendus avalikus elus on marginaalne. Rahvameditsiini Assotsiatsioonist eristab Olohh Siret hiina traditsioonile toetuva vaimsete võimlemisharjutuste kompleksi kuulutamine religiooni selgrooks, aga ka mõningate rituaalide erinev tõlgendus ning - last but not least isiklikud vastuolud liidrite vahel. Peale selle eksisteeris ja eksisteerib siiamaani šamaane, kes ei kuulu kumbagi ühendusse. Minu pealiskaudsete vaatlusandmete järgi võib neid kohata ennekõike Jakuutia väikerahvaste evenkide, eveenide ja dolgaanide külades. Tihti ei ole nende positsioon oma kogukonnas üheselt mõistetav: on inimesi kes on nende võimete suhtes skeptilised, aga leidub ka kogukonnaliikmeid, kes usuvad oma küla šamaani võimetesse kaljukindlalt. Välitöödel Loode-Jakuutia dolgaanide juures jäi mul mulje, et enamik külaelanikest ei võtnud oma küla šamaani eriti tõsiselt, kuni endal häda käes oli. Siis mindi nii arsti kui ka šamaani juurde. Samas on nii jakuudi kui ka Lääne uurijad mulle eravestlustes kinnitanud, et nende meelest etniliste jakuutide külades enam praktiseerivaid šamaane pole (vestlused Piers Vitebsky, Marjorie Mandelstam-Balzeri, Anatoli A. Aleksejevi ja Uljana Vinokurovaga 2001-2008).

Rahvameditsiini Assotsiatsiooni juht ja jakuudi neo-šamanismi liider Vladimir Kondakov oli endine marksismi-leninismi õppejõud, kes 1990. aastate algul sai sahha "tagasi esivanemate usu juurde" liikumise mitteformaalseks juhiks ja ideoloogiks. ${ }^{8}$ V. Kondakovi muundumist marksismi-leninismi õppejõust usuliidriks katab salapära, ta ise vältis igasuguseid selgitusi sel teemal ja keeldus viimastel aastatel üldse meediaga suhtlemast. V. Kondakov on loonud oma kontseptsiooni jakuudi traditsioonilisest religioonist, mis on muutunud Rahvameditsiini Assotsiatsiooni ametlikuks ideoloogiliseks platvormiks. Minu poolt intervjueeritud folkloristide ja etnograafide sõnul on V. Kondakov üsna vabalt korjanud muuseumite kogudest rituaalide kirjeldusi, sobitanud need folkloristide kogutud rituaalsete tekstidega ning lisanud elemente mitmest ida usundist ja teiste siberi rahvaste šamanistlikest traditsioonidest. V. Kondakov ise olevat olnud aga seisukohal, et tema rekonstruktsioon jakuudi muinasusun- 
dist on kõige autentsem. V. Kondakovi loodud organisatsioonis on range hierarhia ja struktuur. Tema ja ta lähikondlased on viimase 15 aasta jooksul avaldanud hulga raamatuid, mis tutvustavad lugejaile jakuutide "muistset" usku ning propageerivad rahvuslikkust ja patriotismi (Kondakov 1998). Uue ideoloogia nimi on Aiõõ itegel ehk loodus- (või ka esivanemate) usk, ja see sisaldab hulga ettekirjutusi, millest eriti veendunud usklikud ka kinni peavad. Siia kuulub näiteks tervislike eluviiside nõue, mis on vägagi ajakohane Siberis, kus alkoholism on üldine probleem. Samuti kuulub sahha esivanemateusu juurde üsna karm moraalinormide koodeks, mille eesmärk on tagada püsiva ja terve perekonna säilimine ning kestmine. Jakuudi esivanemateusulistel on olemas isegi oma gümnastika, mille harjutajaid võib vahest näha varastel hommikutundidel Jakustkis Leena jõe kaldapealsel. Oma olemuselt on assotsiatsioon ühendus, mis säilitab ja arendab edasi vana jakuudi rahvameditsiini ning propageerib jäägitult loodusravi. Ametlikes dokumentides ei tarvitata kusagil sõna “Šamaan” või "šamanism” ei vene ega jakuudi keeles.

Nagu ma edaspidi näitan, võib väita, et Rahvameditsiini Assotsiatsiooni liikmed tegelevad ravimisega, kuid osa nende tegevusest võib klassifitseerida ka rituaalse šamanismina, viimasega astutakse üles suisa riikliku tähtsusega avalikel üritustel. Jakuutias töötatud aastate jooksul on mulle jäänud mulje, et tavainimene assotsiatsiooni kõrgkihiga isiklikult kokku ei puutu. Mul ei ole andmeid, et mõni Rahvameditsiini Assotsiatsiooni liige oleks läbi viinud šamanistlikke tseremooniaid mujal kui avalike ürituste käigus. Sellest hoolimata kutsutakse neid inimesi oiünideks ehk šamaanideks, kuigi seda tehakse pooltõsiselt. Sama pooltõsiselt vastavad inimesed, kui neilt küsida, kes on V. Kondakov: “Ta on Jakuutia peašamaan." Seega võib nentida, et kuigi Rahvameditsiini Assotsiatsiooni kui šamanistliku ühenduse roll on tavasahha elus minimaalne, peetakse just rituaalide läbiviimisega seotud isikuid pigem šamaanideks.

Samal ajal kui mitteformaalsed usuliidrid hoolitsevad rahva vaimse ja füüsilise tervise ning moraali eest, on oma tegevust selles valdkonnas intensiivistanud ka riik. Alates aastast 2000 alustas Sahha Vabariigi valitsus tollase presidendi Mihhail Nikolajevi juhtimisel nn tervislike eluviiside kampaaniat, mille eesmärk oli piirata alkoholi ja tubaka tarbimist, kannustada rahvast tegelema spordiga ja hoolitseda perekonna terviklikkuse eest. Kõik need initsiatiivid käivitati rahvuslikku retoorikat kasutades rahva tervise ja tuleviku nimel. Rahvameditsiini Assotsiatsioon pakkus riigile tema kampaaniates ideoloogilist tuge, mis aitas kindlasti mobiliseerida inimesi riigi tervisetõstmise poliitikaga ühinema. Selles suhtes leidis Sahha Vabariik omale Rahvameditsiini Assotsiatsioonis liitlase, kellele toetumine on pikemas perspektiivis kasulik. 


\section{Meditsiin, poliitika, kultuur ja identiteet}

Rahvameditsiini Assotsiatsiooni roll sahha inimeste elus on mitmekülgne. Assotsiatsiooni liikmed tegelevad sõna otses mõttes rahvameditsiiniga, samas on organisatsioon avalikus elus tähtis kultuurilis-rahvusliku institutsioonina. Kõigepealt kirjeldan antud institutsiooni meditsiinilist tegevust.

Minu välitöö ajal 2001. aasta aprillis saabus Kesk-Jakuutiast Anabari rajooni jakuudi ravija (emtšit), kes oli Rahvameditsiini Assotsiatsiooni ametlik liige. Seda tõestas ta assotsiatsiooni liikmepiletit ette näidates. Pärast seda ümbritses teda nii elanikkonna kui ka ametivõimude austus ja vastutulek. Kõigepealt näidati ravija reklaami kohalikus (rajooni) televisioonis. Reklaamis kuulutas ravija, et ta ravib raha eest teatud haigusi ning lisatud oli ka haiguste nimekiri, millega ta arvas end toime tulevat. Peale alkoholismist ja suitsetamisest vabastamise kuulusid antud ravija ampluaasse veresoone-, silma- ja liigesehaigused, samuti mitmed siseelundite ja vanadusega seotud haigused. Samasisulised plakatid riputas ravija üles ka küla administratsiooni, poodi ja mitmesse muusse strateegilisse punkti.

Mina kohtusin sama ravijaga Anabari rajooni kõrvalises külas Jurjung Haias (tegemist on venekeelse nimevormiga, jakuudikeelne kohanimi kõlab Üürüng Haia), kuhu ta oli saabunud rajoonikeskusest. Kui ma jälle külakeskusse läksin, et sovhoosi esimehega nõu pidada, avastasin tema kabinetist vanema mehe, kes seal oma kotti lahti pakkis. Jutu käigus selgus, et tema ongi ravija, kes oma nii 30 aastate alguses naisabilisega on Põhja lennanud. Sovhoosi esimees, 24-aastane dolgaani noormees, oli jätnud oma kabineti ravija käsutusse ja ajas oma ametiasju raamatupidaja ruumides. Ravija ja tema abiline ööbisid esimehe kabineti põrandal ja korraldasid päeval ravimisseansse. Paralleelselt sellega pidas ravija Jurjung Haia kultuurimajas mõned avalikud ja tasuta loengud, kus rääkis tervislikest eluviisidest ja rahvameditsiinist. Nagu hiljem direktorilt kuulsin, oli ravija kohe saabudes temaga kontakteerunud ja esitanud ka Rahvameditsiini Assotsiatsiooni liikmepileti, tõendades sellega, et tal on volitused rahvameditsiini praktiseerijana inimesi ravida.

Minule jutustas ravija, et ta lähtub oma ravimismeetodites vanast jakuudi rahvameditsiinist, mida segab hiina meditsiiniga. Jakuudi meditsiini oli ta õppinud nii oma koduküla ravijatelt kui ka jakuudi rändravijatelt. Hiina meditsiini teadmised pärinesid tal Jakutskit külastanud hiina ravijatelt, kes olid korraldanud ka tasulisi kursusi. Meie jutuajamise kõige huvitavamal hetkel saabus aga noor sovhoosiesimees, kes teatas, et ukse ette oli kogunenud juba hulk rahvast, kes ootasid ravija ette pääsemist. Kohe kutsuti viis inimest sisse ja ravija hakkas neid küsitlema. Esialgsed küsimused olid samad nagu tavali- 
se arsti juures, ravijat huvitas patsiendi vanus, kas ta suitsetab, perekonnaseis jne. Mingil hetkel paluti minul lahkuda ja nii jäi mul ravimisprotsess nägemata. Hiljem jutustas mulle üks mu informantidest, kes käis seal oma silmi ravimas, et ravimisprotsess oli kiire ja efektiivne, tema sai oma silmade tilkumisest kohapeal lahti. Ka ei olnud ravimine ühele inimesele liiga kallis, temalt oli ravija võtnud 200 rubla, mis tundraküla ülikõrgete hindade juures oli mõõdukas summa ja mida sealsed vaesed inimesed suutsid endale lubada. Ka järgmisel päeval oli sovhoosi kontoris pikk saba abiotsijatest, kes päeva jooksul ravija juurde pääsemist ootasid. Nii või teisiti olid paljud inimesed ka abi saanud, ehkki mitmed meespatsiendid, kes läksid saama rohtu suitsetamise ja alkoholitarbimise vastu, hakkasid mitu kuud hiljem jälle suitsetama ja jooma.

Ravija külaskäik oli ja jäi tükiks ajaks suursündmuseks Jurjung Haia elus. Sellest räägiti omavahel teetassi ümber ning arutati, kes külaelanikest mis haiguste vastu rohtu otsimas käis. Ükski inimene, kellega ma ravijast rääkisin, ei seadnud kahtluse alla tema võimeid. Ravijast rääkides kasutasid inimesed aupaklikku tooni ja nalja tema üle ei visatud.

Institutionaalses plaanis puutusin Rahvameditsiini Assotsiatsiooniga kokku varem - Jakuutia pealinnas Jakutskis. Minu saabudes 2000. aasta juunis olid Jakustkis parajasti algamas Aasia Laste Olümpiamängud. Linnale anti viimast lihvi, värviti aedu ja pügati haljasaladel muru. Paari päeva pärast oli mul võimalus televisiooni vahendusel jälgida olümpiamängude avatseremooniat. Nagu päris olümpiamängudel, marssisid Siberi erinevate regioonide ja välisriikide meeskonnad staadionile ning rivistusid üles. Siis esitati peo avamistantsud-mängud, mis kirjeldasid Jakuutia ajalugu ja põhinesid jakuutide rahvuseeposel Olonhool. Pärast seda astus väikesele lavale Jakuutia "peašamaan" ja Rahvameditsiini Assotsiatsiooni juhataja Vladimir Kondakov koos oma abilistega. Kõik olid valges riides ja kandsid traditsioonilisi koonilisi peakatteid. Astudes mikrofoni ette, sooritas Kondakov avapalvuse ning siis viidi väikesel lõkkel läbi ohverdamistseremoonia, kus traditsioonilisest jakuudi peekrist $t$ šoronist kallati lõkkesse kumõssi.

Teist korda nägin V. Kondakovi juba otse, ilma televiisori vahenduseta. See oli jakuudi suvisel pööripäeval õsõeahil ${ }^{9}$. See pidustus on sama vana ja traditsiooniline kui eestlaste jaanipäev ning sarnaselt jaanipäevale on ka õsõeah erinevatel perioodidel muutunud. Jakuudi õsõeahi keskne sündmus on suurte lõkete põletamine ning vastu hommikut tervitab kogunenud rahvas tõusvat päikest. Nõukogude ajal muutus õsõeah tavaliseks rahvapidustuseks, mida peeti igas asulas. Nagu paljud informandid mulle jutustasid, alustati kohe pärast nõukogude võimu tagasitõmbumist tasapisi õsõeahil religioossete rituaalide korraldamist. Kui mina sattusin esimest korda elus Jakutski linnaõsõeahile, 
oli seal peoplatsi serval terve šamaaniküla. Jakutski linnaõsõeahi peetakse terve Sahha Vabariigi kõige olulisemaks suvise pööripäeva pidustuseks ning see on ka ainukene õsõeah Sahha Vabariigis, mille avamisel viibib vabariigi poliitiline kõrgkiht alates presidendist endast.

Pidustused toimuvad linnast väljas suurel mitmeruutkilomeetrisel platsil. Platsi sissepääsu kohale olid rajatud suured nikerdatud tseremoniaalsed väravad, mille kohta mu kaaslased ütlesid, et aasta tagasi neid veel polnud. Platsil olid müügiletid, välikohvikud, hobuste võidusõidurada ja enam kui kümme lava kus vahetpidamata esinesid lauljad ning muusikakollektiivid. Peoplatsi tagaservas asus väike sopka (lameda tipuga mägi) mille teisel pool asuski nn šamaaniküla. Mägi oli piiratud puutaraga, mille sees asusid tseremoniaalpostid serged ${ }^{\mathbf{1 0}}$. Minu üllatuseks oli šamaaniküla üsna suur. Seal oli mitu suurt telki, kus viidi läbi puhastustseremooniaid. Järjekord nende telkide ees oli üsna pikk. Siis oli veel väiksemaid onne, kus ravijad inimesi ravitsesid või siis ka neile ennustasid. See osa platsist oli rahvast täis ja inimesi tuli kogu aeg juurde.

Hommikupoole, kui hakkas lähenema päikese tervitamise tseremoonia aeg, kogunes rahvas sopkat ümbritseva piirdetara taha. Mõni tund enne päikesetõusu tulid mäetipule valges riides nooršamaanid ning pärast mõne "traditsioonilise" tantsu esitamist algas tunde kestev ohvritseremoonia mäe tipus asuva ohvrikivi ümber, mille ees põles lõke. $\mathrm{Mu}$ sõbrad ütlesid, et eelmistel aastatel polnud ohvrikivi ega ohvrituld. Tseremoonia lõppes päikesetõusuga, mida kogu rahvamass tervitas ülestõstetud kätega. Peab veel kord mainima, et päikese tervitamise tseremoonia šamaanide osavõtul oli riigi kõige tähtsama õsõeahi programmi ametlik osa ning sellel viibis ka mitmeid inimesi sahha eliidist, kuid mitte president oma kaaskonnaga. Huvitav oli see, et kui ma hiljem näitasin inimestele oma videosalvestisi õsõeahist ja palusin endale selgitada nii rituaale, nende läbiviijaid kui ka nende riietust, erinesid seletused rituaalide, nendega seotud isikute ja sümbolite tähendusest kohati radikaalselt. Rituaale, mida osa inimesi pidas formaalseks või suisa väljamõeldiseks, pidasid teised ehtsaks, ent naersid nende rituaalide või isikute üle, mida esimesed pidasid ehtsateks ja traditsioonilisteks.

2006. aasta suvel oli õsõeah veel pompöössem, aga vähem folkloorne. Hoolimata sahha estraadi väga etnilisest iseloomust (vrd Ventsel 2004a, 2004b) oli jakuudi identiteedi manifestatsiooniks ka 2006. aastal programmi tõsised osad. Et äsja oli jakuudi rahvuseepos Olonhoo kuulutatud UNESCO maailmakultuuri pärandi üheks osaks, oli õsõeahi avatseremoonia suurejooneline näitemäng Olonhoo ainetel. Kohal viibisid peale presidendi ka USA ja Prantsusmaa saadikud Venemaal, suurte vene linnade (Moskva, Sankt-Peterburg) esindajad ja palju muid tähtsaid ametiisikuid. Enne tribüünidele minekut läbisid nad 
puhastustseremoonia, mille viis läbi V. Kondakov ise. Ehkki enamik külalisi ei jäänud päikese tervitamise tseremooniale, oli ka see rituaal eelmiste aastate omast tõsisem, sinna oli lisatud järjekordselt jakuudi indentiteete rõhutavaid elemente (uued "rituaalsed" tantsud, eriti pikk ringlaulu uosohhai laulmine jne). 2006. aasta õsõeah oli vähem püha (sakraalne) ja rohkem meelelahutuslik kui oli olnud 2001. aastal. Puhastustelgid olid ka 2006. aastal, ent enamik inimesi näisid rohkem huvituvat suurest toidutänavast, suveniiriputkadest, spordivõistlustest ja estraadikontsertitest. Samas oli tegemist sahha identiteeti rõhutava festivaliga, analoogiliselt rahvusprojekti kaasatud analoogilise kesksuve tähistamise festivali Surkhabaniga Burjaatias (Krist 2004, 2009). Jakuutide puhul olid õsõeahi kesksed sündmused sahha rahva ajaloolis-religioosse eepose teatraalne esitamine ja päikese tervitamine valgete šamaanide juhtimisel.

\section{Kokkuvõtvad märkused}

Seos identiteedi, ideoloogia, majanduse ja postsotsialistliku rahvusriigi vahel ei vaja erilist selgitamist (Harding 1992; vt Gitleman 1992). Sahha Vabariik ei ole ainukene Vene Föderatsiooni regioon, mis rahvusliku sümboolika kasutuselevõtuga püüdis oma mitte-vene identiteeti võimalikult esile tõsta (vrd Anderson 1998). Nagu iga riik, lõi ka Sahha Vabariik oma riigiidentiteedi, lähtudes nii ajaloolistest faktidest kui ka legendidest (Hobsbawm \& Ranger 1983). Üks sahha rahva identiteedi alus oli kontseptsioon jakuutidest kui erilisest põhjamaisest sõdalasrahvast, kelle olemus ja päritolu on müstiline (Vinokurova 1994; Ksenofontov 1992; Vorobjova \& Spiridonov 2003). Põhjamaiste sõdalaste juurde kuulusid jakuutide arvates ka võimsad ja salapärased šamaanid. Et nõukogude ajal ei suudetud traditsioonilisi jakuudi religioosseid uskumusi välja suretada ja paljusid neist praktiseeriti kas avalikult või varjatult kogu nõukogude perioodi jooksul, ei kohanud ka Rahvameditsiini Assotsiatsiooni loomine ja avalikku ellu astumine jakuutide seas mingit vastupanu või tõrjumist.

Ma ei väida, et Rahvameditsiini Assotsiatsioonile poolriikliku staatuse andmine oli esimese Jakuutia presidendi Mihhail Nikolajevi kaalutletud strateegiline samm rahva lojaalsuse võitmiseks. Selles suhtes ei ole ma nõus Georg Elwertiga, kes väidab, et identiteetide loomine ja nendega manipuleerimine on külmalt kalkuleeritud (Elwert 2002: 33-34). Pigem tähendas see mitme kihistuga situatsioonist tingitud spontaanset poliitikat, nagu leidis aset ka teistes postsotsialistlikes piirkondades (Hann jt 2002: 13-14). Kaasates V. Kondakovi riiklikesse tseremooniatesse, rõhutas president $M$. Nikolajev sellega oma rii- 
gi sahha identiteeti. Muidugi tähendas see ka sahha rahvuse eksponeerimist, näidates, et tegemist on muistse kultuurrahvaga. Me peame arvestama, et Sahha Vabariigi algusaastad olid emotsionaalselt sama eufoorilised kui olid Eesti Vabariigi algusaastad, ja rahvusvaimustuses demonstreeriti nii Eestis kui ka Jakuutias oma rahvusliku identiteeti mõnevõrra ülepingutatumalt kui see on kombeks juba kinnistunud identiteediga ja stabiilse riigiga rahval.

Teisalt andis nn iidsete rituaalide kaasamine Sahha Vabariigi tseremooniatesse presidendile ja valitsusele võimaluse näidata ennast kogu sahha rahva ja nende kultuuri esindajatena. Selline samm legitimeeris valitseva seltskonna positsiooni rahva silmis. See aga ei seleta Rahvameditsiini Assotsiatsiooni staatust. Pärast suveräänsete vabariikide väljakuulutamist aktiviseerusid neošamanism ja neošamanistlikud organisatsioonid mitmel pool endises Nõukogude Liidus. Sellest hoolimata ei saavutanud nad kusagil sellist peaaegu riigiinstitutsiooni staatust kui Jakuutias. Riiklikul tasandil rõhutati Jakuutias kõike rahvuslikku ning V. Kondakov kasutas ära soodsat situatsiooni. Usuliidrina oli ta huvitatud sahha religiooni ja religioossete rituaalide suuremast esindatusest Sahha Vabariigi avalikus elus. Et Rahvameditsiini Assotsiatsiooni viljeldavad rituaalid ja manipuleeritud traditsioon sobisid hästi jakuutide ettekujutusega oma ajaloost ja kultuurist, andis see V. Kondakovile ja tema organisatsioonile võimaluse võita nii sümboolset kui ka poliitilist kapitali. Selle läbi suurenes ka Rahvameditsiini Assotsiatsiooni ligipääs ressurssidele. Ma ei mõtle siin mitte ainult riiklikku finantseerimist, mis kindlasti mingis ulatuses eksisteerib, vaid ka võimalust üksikutel assotsiatsiooni liikmetel tegutseda legaalselt praktiseerivate arstidena.

Jonathan Friedman näitab Kreeka ja Havai võrdluses, et rahvusidentiteedi loomiseks on võimalik Lääne (euroopalikku) kontseptsiooni nii ära kasutada kui ka eirata (Friedman 1992). Endise nõukogude ideoloogilise eliidi liikmena ei asunud V. Kondakov üksnes looma uusi teid sahha identiteedi sidumiseks "traditsioonilise" kultuuriga, vaid kasutas ära ka olemasolevad võimustruktuurid, mille iseloomu ja funktsioneerimise aluseid tundis ta juba nõukogude ajast. Oma poliitilise positsiooni kindlustamiseks, hoidmiseks ja tugevdamiseks lähenes ta jakuudi religioossele traditsioonile loovalt. Eriti hea näide rituaalse üldpildi pidevast täiendamisest ja sellega manipuleerimisest, et rõhutada Rahvameditsiini Assotsiatsiooni olemasolu ja osalust riiklikes sündmustes, on õsõeah. V. Kondakov suutis siduda Rahvameditsiini Assotsiatsiooni olemasolevate riiklike esindustseremooniatega, kusjuures väga kõrgel tasemel (vabariiklik õsõeah, Aasia Laste Olümpiamängud), murdes paljude ambitsioonikate liidrite kombel võimupüramiidi tippu (vrd Anderson 1999: 90-91). President M. Nikolajevi poliitika viis selleni, et institutsionaliseeritud šamanism 
muutus jakuudi rahva identiteedi manifestatsiooniks ning inimesed aktsepteerivad seda sellisena tänini.

\section{Kommentaarid}

1 Enamiku artiklis kasutatud materjalist kogusin Halles, Saksamaal paikneva Max Plancki nimelise Sotsiaalantropoloogia Instituudi finantseeritud välitöö käigus aastail 2000-2001, mil tegin uurimistööd Jakutski linnas, Anabari, Tšurapsinski ja Topolinski ulussis. Antud välitöö teemaks olid omandisuhted ning enamik selles artiklis esitatud materjalist on selle välitöö "kõrvalprodukt" (vt Ventsel 2005, 2003, 2001, 2002; Stammler \& Ventsel 2003). Lisamaterjali kogusin Jakutskis ja selle ümbruses 2006. aasta suvel ja 2007. aasta kevadel. Seda välitööd finantseeris neli projekti: Eesti Kirjandusmuuseumi jätkudoktori projekt "Mitteformaalsed võrgustikud, etniline identiteet ja muusikakultuur postsotsialistlikus Jakuutias", mis teostati SF teema "Eesti ja teiste rahvaste folkloor: pärimus, identiteet ja globaliseerumine" juures, ETF grant "Religioossed muutused postkolonialistlikus maailmas", EUROCORES'i programmi Boreas projekt "New Religious Movements in the Russian North: Competitive Uses of Religiosity after Socialism (NEWREL)" (FP007) ja Euroopa Liidu Euroopa Regionaalarengu Fond (Kultuuriteooria Tippkeskus).

${ }^{2}$ Rahvuse moodustamise projekt on siin otsetõlge ingliskeelsest nation building project. Tegemist on kindla tähendusega (ehkki Eesti teaduses vähetuntud) terminiga, mis tähendab riigipõhise identiteedi tekitamist eliidi poolt riigi elanikke ühendavate ühisnimetajate loomise läbi. Eestikeelse terminoloogilise segaduse kohta vt ka kommentaari 4.

3 Selles artiklis kasutan etnonüüme "sahha" ja "jakuut" vaheldumisi ja samatähenduslikult.

4 Terminit 'rahvus' mõistan siinkohal analoogina ingliskeelsele reminile 'nation' ehk siis riigiidentiteediga seotuna. Et teatud inimrühmal tekiks rahvusidentiteet, ei pea ta tingimata olema iseseisva rahvusriigi ehk 'nation state' subjekt. Ajaloos leidub piisavalt näiteid, kus teatud etnilistel rühmadel tekkis rahvusidentiteet hoolimata tõsiasjast, et nende territoorium oli de jure ja de facto osa teise riigi territooriumist (vrd baskid, katalaanid, kurdid, šotlased). Rahvusidentiteet võib tekkida ka suveräänsel või autonoomsel territooriumil nagu see on toimunud ka jakuutidega (vrd Anderson 1999: 99-91; Hobsbawm \& Ranger 1992). 'Rahvuskultuuri' all mõistan antud teksti raames riigi poolt toetatud ja riigi tekitatud kultuurilisi ühisnimetajaid, mille eesmärk on koondada inimesed ühise riikliku moodustisega seotud identideedi ümber.

${ }^{5}$ Didgeridoo (didžeriduu) on vana Austraalia aborigeenide instrument, mida on mängitud juba aastatuhandeid. See on termiitide poolt õõnsaks söödud puust või bambusest kuni 2 meetri pikkune puhkpill, mille põhiheli on madal jorin. Heli saab muuta suuõõne ja huuleasendi muutmisega.

${ }^{6}$ Õnnistus ehk algõs on mõeldud vaimude positiivse tähelepanu äratamiseks õnnistatava suhtes. Jakuudi traditsioonis on tegemist eriti ohtliku religioosse rituaaliga, 
mille valesti sooritamine võib tuua paljudele (ka asjaga mitte seotud) isikutele hoopis ebaõnne. Eriti ohtlik on see, kui loitse esitavad mittešamaanid.

7 Sõna "iidne" kasutan siinkohal jutumärkides põhjusel, et rahvale demonstreeriti vaid valikulisi ja vaieldavaid seiku jakuudi ajaloost, mis sümboliseerisid just jakuudi etnose ülevat ajalugu. Mitmed arheoloogid on mulle eravestlustes väitnud, et legend jakuutidest kui sõdalasrahvast pole siiani kinnitust leidnud. Samuti puudub tõendusmaterjal, et kunagi oleks eksisteerinud mingisugunegi jakuudi impeerium või et jakuudi šamaanid oleksid keskajal või hiljemgi millegi erilisega silma paistnud.

8 Vladimir Kondakov suri ootamatult 14. juulil 2009. Tema järglane on siiamaani valimata, assotsiatsiooni netilehekeüljel on presidendiks endiselt V. Kondakov, vt http://aaraiyyitegele.ru/ (viimati vaadatud 22.03.2010).

9 Antud termini kohta on käibel mitmed nimevormid. Siin tekstis kasutatud õsõeah on pigem jakuudi lõunamurdeis ja kirjakeeles kasutatav nimetus, põhjamurdeis öeldakse õheah ning vene keeles kasutatakse sõna õsõah, inglise keeles on levinud väljend ysyeakh.

${ }^{10}$ Serge oli algselt nikerdatud post hobuste sidumiseks. Tänapäeval on sergel dekoratiivne või sümbolistlik iseloom ning ta on üks sahha identiteedi väljendajaid. Neid püstitatakse ametiasutuste ette, koduõue laste sünni tähistamiseks, peoplatsidele piduliku miljöö loomiseks jne.

\section{Kirjandus}

Anderson, Benedict 1999. Imagined Communities. London \& New York: Verso.

Anderson, David G. 1998. Living in subterranean landscape: identity politics in postSoviet Khakassia. Bridger, Sue \& Pine, Frances (toim). Surviving Post-Socialism. Local strategies and regional responses in Eastern Europe and the former Soviet Union. London \& New York: Routledge, lk 52-65.

Balzer, Marjorie Mandelstam 1993. Shamanism and the Politics of Culture: An Anthropological View of the 1992 International Conference on Shamanism, Yakutsk, the Sakha Republic. Shaman 1 (2), lk 71-96.

Bravina, Rosalia I. 2005 = Бравина Розалия. Концепция жизни и смерти в культуре этноса. На материале традиций Саха. Новосибирск: Наука.

Bulgakova, Tatjana [Tatiana] D. 2009. From Drums to Frying Pans, From Party Membership Card to "Magic Branch" Withe: Three Generations of Nanai Shamans. Folklore: Electronic Journal of Folklore 41, lk 79-96.

Castaneda, Carlos 1971. A Separate Reality: Further Conversations With Don Juan. Washington: Washington Square Press.

Castaneda, Carlos 1968. The Teachings of Don Juan. A Yaqui Way of Knowledge. Washington: Washington Square Press. 
Duncan, Peter J. S. 1994. The politics of Siberia in Russia. Sibirica 1, lk 13-23.

Elwert, Georg 2002. Switching identity discourses: primordial emotions and the social construction of we-froups. Schlee, Günther Imagined differences. Hatred and the construction of identity. Münster \& Hamburg \& London: LIT, lk 33-54.

Forsyth, James 1992. A History of the Peoples of Siberia. Russias North Asian Colony 1581-1990. Cambridge: Cambridge University Press.

Friedman, Jonathan 1992. The Past in the Future: History and the Politics of Identity. American Anthropology 94 (4), lk 837-859.

Gitleman, Zvi 1992. Development and Ethnicity in the Soviet Union. Motyl, Alexander J. The Post-Soviet nations. Perspectives on the Demise of the USSR. New York: Columbia University Press, lk 221-239.

Hann, Chris \& Humphrey, Caroline \& Verdery, Katherine 2002. 'Farewell to the Socialist "Other"', First Part of 'Introduction. Postsocialism as a topic of anthropological investigation'. Hann, Chris (toim). Postsocialism. Ideals, ideologies and practices in Eurasia. London: Routledge, lk 1-28.

Harding, Neil 1992. Legitimations, Nationalities and the Deep Structure of Ideology. Motyl, Alexander J. The Post-Soviet Nations. Perspectives on the Demise of the USSR. New York: Columbia University Press, lk 79-96.

Harner, Michael 1980. The Way of the Shaman. San Francisco: Harper \& Row.

Harner, Michael 1999. Science, Spirits, and Core Shamanism. Shamanism 12 (1).

Hobsbawm, Eric J. \& Ranger, Terence O. (toim) 1992. The Invention of Tradition. Cambridge: Cambridge University Press.

Khazanov, Anatoly M. 1995. After the USSR. Ethnicity, Nationalism, and Politics in the Commonwealth of Independent States. Maddison: The University of Wisconsin Press.

Kondakov, Vladimir 1998 = Кондаков, Владимир. Ойууннааһын эйгэтин кистэннэрэ. Якутск: Бичик.

Krist, Stefan 2004. Where going back is a step forward: the re-traditionalising of sport games in post-Soviet Buriatiia. Sibirica 4 (1), lk 104-115.

Krist, Stefan 2009. Kickboxing, Breakdance and Pop Music versus Wrestling, Round Dance and Folk Music? Popular Culture in Buryatia Today. Folklore: Electronic Journal of Folklore 41, lk 131-142.

Ksenofontov, Gavriil 1992 = Ксенофонтов, Гавриил. Ураангхай-сахалар: очерки по древней истории якутов. 1 \& 2. Якутск: Национальное издательство республики Caxa.

Mowat, Farley 1970. The Siberians. London: Heinemann.

Stammler, Florian \& Ventsel, Aimar 2003. Between Neo-Liberalism and Dirigisme: Approaches to Reindeer Herding in Yamal and Sakha. Hann, Chris (toim). The Postsocialist Agrarian Question. Property Relations and the Rural Condition. Münster: LIT Verlag, lk 321-363. 
Tichotsky, John 2000. Russia's diamond colony. The Republic of Sakha. Amsterdam: Harwood Academic Publishers.

Tõrõlgin, Mihhail 2000 = Тырылгин, Михаил. Истоки феноменальной жизнеспособности народа Саха. Якутск: Бичик.

Ventsel, Aimar 2001. Property and Informal Social Relations in a Dolgan Village (Sakha Republic). Max Planck Institute for Social Anthropology. Report 1999-2001. Halle/Saale: Max Planck Institute for Social Anthropology, lk 120.

Ventsel, Aimar 2002. Surviving in the North. Meaning of kinship among the Dolgans in North Western Yakutia. Nauka i Obrazovanie 26 (2), lk 54-57.

Ventsel, Aimar 2003. People Won't dance if They have Nothing to Eat: Do Economic Transformation and Centrally Planned Cultural Revival Fit Together? Polar Geography 27 (2), lk 121-135.

Ventsel, Aimar 2004a. Sakha Pop Music and Ethnicity. Kasten, Erich (toim). Properties of Culture - Culture as Property. Pathways to Reform in Post-Soviet Siberia. Berlin: Dietrich Reimer Verlag, lk 67-86.

Ventsel, Aimar 2004b. Stars without money: Sakha ethnic music business, upward mobility and friendship. Sibirica 4 (1, April), lk 88-103.

Ventsel, Aimar 2005. Reindeer, Rodina and Reciprocity: kinship and property relations in a Siberian village. Halle/Saale: LIT Verlag.

Vinokurova, Uljana 1994 = Винокурова, Ульяна. Сказ о народе саха. Якутск: Бичик. Vorobjova \& Spiridonov 2003 = Воробьева, Е \& Спиридонов, Г. Не забыть свои истоки... Якутия 29. 04. 2003, 8.

\section{Summary}

\section{Sakha (Yakut) Identity and Institutionalised Shamanism}

\section{Aimar Ventsel}

Key words: ethnic identity, Sakha religion, shamanism

In this article I discuss the ambivalent position of institutionalised shamanism in the Republic of Sakha, in the Russian Far East. Concurrently with the declaration of sovereignty in 1991, there was an upswing in the ethnic consciousness of the Sakha, the relevant process being manifested in increased interest in Sakha traditions and history.

Shamanism, as one of the core features of Sakha culture, soon became an important ethnic symbol. After the establishment of the Association of Folk Medicine, the 
institution became politicised, being informally embedded in state structures, although formally, it was primarily engaged in healing people.

I show that the state needed the Association to complete its nation building project, and the Association leaned on the state to increase its significance. 